\title{
The salience of silent letters in children's memory for word spellings
}

\author{
LINNEA C. EHRI and LEE S. WILCE \\ Department of Education, University of California, Davis, California 95616
}

\begin{abstract}
To compare children's memory for silent and pronounced letters in familiar spellings of words, 7- to 10-year-olds were given two tasks. First, they imagined word spellings and decided whether target letters were present. Then they recalled the words associated with the target letters. Five experiments yielded similar findings. Pronounced letters were recognized somewhat more accurately than silent letters. However, silent letters were detected more rapidly in words than pronounced letters were, and silent letters prompted superior recall of words. The influence of several factors, such as the particular words chosen, the position of letters, and the expectancies of subjects, was ruled out in one or another experiment. Two explanations for findings are proposed. The favorite is that effects reflect the way silent letters are stored in long-term memory when spellings are learned. The other is that events occurring in the experiment enhanced episodic memory for silent letters.
\end{abstract}

One of the properties of English word spellings that is especially bothersome to beginning readers concerns letters that do not symbolize any sound in a word's pronunciation. Although in a linguistic analysis some silent letters (e.g., final E) may be considered to participate in functional spelling units that as a whole map sounds systematically (Venezky, 1970), it is doubtful that beginning reader/spellers are aware of or use such complex spelling-sound relationships. More likely, if beginners cannot find a separate sound for a single letter and if they do not see it as part of a digraph (e.g., sh, ch, th), then the letter is regarded as silent. Categorization of letters as "silent" is probably a common explanation given to beginning readers and spellers when they stumble over letters lacking a correlate in sound. Rather than attempt a complicated and possibly futile explanation regarding how one letter changes the pronunciation of another, teachers in the early grades and also parents are likely to assert simply that the letter is silent. That this distinction may be acquired early is suggested in Chomsky's (1979) observation of her own preschooler, who saw the word "Joan," sounded it out as "Jane," and upon learning of his mistake explained, "Oh, I see. The A is silent. I thought the O was silent." To the extent that unpronounced letters are learned as silent rather than as instances of complex spelling rules, their occurrence must appear

This research was supported by Grant NIE-G-77-0009, awarded by the National Institute of Education, and Grant HD-12903-01, awarded by the National Institute of Child Health and Human Development. We express our gratitude to the Davis Unified School District and to St. James Elementary School in Davis for their cooperation. Authors' address: Department of Education, University of California, Davis, California 95616. capricious, a property unique to those printed words containing them. Because silent letters are characteristic of many English words encountered by children as they learn to read, it is important to examine whether these letters are more difficult to learn and remember than pronounced letters are. This was one purpose of the present study.

Previous work comparing pronounced and silent letters has left a mixed picture. Also, much of this work has been done with mature readers rather than children. Corcoran $(1966,1967)$ had adults cross out all instances of the letter $E$ as they read a text. Also, he had them proofread a text for misspelled words (Es omitted). He found that in both tasks, silent Es were missed more often than pronounced Es. Venezky (cited in Hatch, Polin, \& Part, 1974) attempted to replicate the cross-out task with the letters $\mathrm{H}, \mathrm{U}$, and $\mathrm{A}$, as well as $\mathrm{E}$, but did not find a silent-pronounced difference. Instead, he found that letters in function words (e.g., articles, prepositions, and conjunctions) were more frequently left unmarked than were letters in content words (e.g., nouns, adjectives, and verbs). Hatch et al. (1974) limited their analysis to content words and found evidence favoring pronounced letters. In a cross-out task, their subjects missed letters in digraphs (e.g., $\mathrm{C}$ in $\mathrm{CH}$ ) more often than single pronounced letters, and they missed letters in unstressed syllables more often than letters in stressed syllables. This pattern held only for subjects proficient in spoken English, not for less competent foreign students. Their explanation is the same as Corcoran's, that acoustic scanning and visual scanning of words operate in parallel and enhance detection of pronounced over silent letters because the pronounced letters are processed twice.

In contrast to the above, Frith (1978) found evidence for the greater prominence of silent letters. She had 
12-year-olds proofread a text in which pronounced and silent letters were omitted from word spellings (e.g., SISSORS for "scissors," SCARELY for "scarcely"). She found that good spellers detected significantly more of the silent- than the pronounced-letter omissions. This result was replicated in a second experiment. Her explanation rests on the fact that silent letters are often more deeply rooted in underlying morphological spelling patterns (e.g., the importance of G in "sign" is signaled by its relationship to "signature"), She suggests that violation of morphological rules may be more easily detected than violation of phonological rules.

Comparison of younger children's memory for silent and pronounced letters has yielded mixed results. In a misspelling detection-correction task, first graders were able to detect the omission of silent letters as well as pronounced letters (Ehri \& Roberts, 1979). In a task requiring subjects to write out made-up words they had previously practiced reading, second-graders recalled pronounced letters better than silent letters (Ehri, 1980a). However, their spellings were not totally phonetic. Rather, there was a tendency to preserve the silent-letter patterns originally seen. For example, GHIRP was recalled always with the $\mathrm{H}$, the $\mathrm{I}$, or both, never GURP or GERP, which are closer to the actual pronunciation. These results indicate that memory for pronounced letters may be superior but that children possess mechanisms for storing silent letters as well.

Ehri $(1978,1980 \mathrm{a}, 1980 \mathrm{~b})$ has proposed a theory of printed-word learning to explain how children learn to read and spell words. The adequacy of this theory as an explanation for silent-letter memory remains unclear, since it regards the sound-symbolizing function of letters as central to their acquisition and retention in memory. According to the theory, as children practice reading words, orthographic images of the pronunciations are formed. These images are thought to be visual, letteranalyzed representations that enter memory when learners recognize how the letters correspond to sound elements buried in the word's pronunciation. If sound correlates for letters cannot be found, then these letters should be harder to store. Eventual success should come, though, since the form of the representation is visual.

Research was undertaken to compare children's memory for silent and pronounced letters in words already familiar to them in print. We reasoned that if children's memory for word spellings is regulated by whether letters symbolize sounds in the words, then pronounced letters should be better known than silent letters. However, if letters are retained in memory without regard for their sound values, then no differences between silent and pronounced letters should be apparent.

\section{EXPERIMENT 1}

The task used to explore children's memory for silent and pronounced letters had three phases and yielded two measures of letter memory. First, children read a list of words to remind them of spellings and to determine which words were in each child's reading vocabulary. Second, children were told to imagine the spellings of these words and decide whether they included particular letters. This was to see whether silent letters were represented in orthographic images as clearly as pronounced letters. Third, each of the letters judged was re-presented and children tried to recall which word they had imagined for that letter. Performance here was interpreted to indicate how prominent the letters were in spellings. It was expected that since pronounced letters symbolize an element in the spoken forms of words, they would be better known than silent letters and would prompt better recall of the words.

\section{Method}

Subjects. Twenty second-graders enrolled in a middle-class elementary school were tested individually in the spring. Half were male, and half were female. Mean chronological age was 91.7 months.

Materials. Selected as target words were 15 high-frequency adjectives and verbs thought to be in the reading vocabularies of second-graders. Each word was assigned a unique letter. For five of the words, a noninitial letter mapping a sound in that word was selected: $n$, kind; $o$, brown; $r$, strong; $i$, sick; $w$, sweet. For five others, a silent letter was selected: a, dead; c, black; 1, talk; g, bright; e, come. For the five remaining words, a letter not present in the spelling was selected: $u$, drink; $z$, jump; $y$, fast; $\mathrm{m}$, hard; $\mathrm{p}$, short. The words appeared in a different random order each time they were presented in the various tasks.

Procedures. First, children read the 15 target words, each printed on a card. If they were unsuccessful on any word, it was pronounced for them, and they continued practicing the words to a criterion of one perfect trial. Few children required more than two trials.

Next, subjects spent 10-15 min performing two filler tasks, a test of word-reading ability and a test of nonsense word decoding from Calfee and Calfee's (Note 1) Interactive Reading Assessment System (IRAS).

Then subjects completed the letter-judgment task. They were instructed how to imagine spellings and to decide whether each contained a letter displayed on a card. The experimenter said, "Now I am going to say the same words that you just read. After I say each word, I want you to say the word and then imagine what it looks like when it's written out. I want you to form a mental picture of the word's spelling in your head so you can see it with your mind's eye. Try to think of all the letters in the word." After practicing with their name, the task began. After children reported "seeing" each word, they were shown a lowercase letter on a card and asked whether the letter was in the word. The words were presented for judgment twice, each time in a different order.

Finally, subjects were surprised with a recall task. Each letter was shown again and children were told to recall the word they had imagined for that letter.

\section{Results}

Children were able to judge whether or not the target words contained the letters almost perfectly. Mean numbers correct for the three letter types are reported in Table 1. Although errors were few, the majority occurred with the silent letters. A matched-pair $t$ test to determine whether more pronounced than silent letters were detected on Trial 1 was significant $[t(19)=2.46$, $\mathrm{p}<.05$ (two-tailed test)]. Scores improved slightly on the second trial, although no feedback was given for incorrect responses. With one exception (i.e., a child 
Table 1

Mean Correct in the Letter-Judgment and Incidental Recall Tasks in Experiment 1

\begin{tabular}{|c|c|c|c|c|}
\hline & \multicolumn{4}{|c|}{ Letters in Words } \\
\hline & Sounded & Silent & Absent & Mean \\
\hline & \multicolumn{4}{|c|}{ Letter-Judgment Task } \\
\hline \multirow[t]{2}{*}{$\begin{array}{l}\text { First Trial } \\
\text { Second Trial }\end{array}$} & $\begin{array}{l}4.85 \\
4.95\end{array}$ & $\begin{array}{l}4.30 \\
4.35\end{array}$ & $\begin{array}{l}4.80 \\
4.80\end{array}$ & $\begin{array}{l}4.65 \\
4.70\end{array}$ \\
\hline & \multicolumn{4}{|c|}{ Word Recall Task } \\
\hline $\begin{array}{l}\text { All Subjects } \\
\text { Subjects With Perfect Letter-Judgment Scores }(N=9)\end{array}$ & $\begin{array}{l}1.70^{*} \\
1.90\end{array}$ & $\begin{array}{l}2.55^{*} \\
2.90\end{array}$ & $\begin{array}{l}.45^{*} \\
.40\end{array}$ & $\begin{array}{l}1.57 \\
1.73\end{array}$ \\
\hline
\end{tabular}

Note-Maximum score $=5 . \quad *$ MSe $(32)=.75$, minimum difference significant $={ }_{n} 58$.

who missed five), no subject judged more than two letters incorrectly on Trial 2 . These results show that silent letters are retained in memory but they are not known quite as well as pronounced letters. This supports the hypothesis that silent letters are harder to preserve in orthographic images than pronounced letters are.

Children had more difficulty recalling the words after the letter-judgment task. Mean values are given in Table 1. A two-way analysis of variance was conducted, with sex as a between-subjects factor, letter type (sounded vs. silent vs. absent) as a repeated measure, and number of words recalled correctly as the dependent measure. A main effect of letter type emerged $[F(2,32)=29.76, p<.01]$. No other effects were significant $(p>.05)$. A post hoc analysis using Tukey's pairwise comparison procedure revealed that all means were significantly different from each other. Surprisingly, silent letters prompted better recall than pronounced letters, which in turn prompted better recall than absent letters. When the recall performance of only the best subjects was considered, that is, those who performed perfectly in judging silent and pronounced letters, the difference between silent- and pronouncedletter recall was even larger (see Table 1). Thus, although silent letters were not judged as accurately as pronounced letters, they nevertheless prompted superior recall of words containing them. These results run contrary to expectations and suggest that silent letters may be more salient in word spellings than pronounced letters are.

Correlations were examined to assess the strength of the interrelationships among several measures: the IRAS measures of printed-word identification and nonsense decoding, accuracy in judging the presence or absence of letters in words, and letter-prompted recall of words. Results revealed significant positive correlations ranging from .58 to $.79(\mathrm{p}<.05)$ among all measures but one. None of the other tasks was significantly correlated with the recall measure (rs ranging from .18 to $.38 ; \mathrm{p}>.05$ ). These findings indicate that knowledge of letters tapped in the letter-judgment task is strongly related to skills regarded as basic in learning to read. These results justify the interpretation of letter-judgment performance as reflecting printed-word acquisition processes. The lack of a relationship between letter-prompted recall performance and the other measures can be interpreted to mean that factors important for acquisition may differ from those important once the letters are secured in memory. Specifically, silent letters may be harder to store but easier to remember once they are learned.

Several additional experiments were conducted in order to replicate findings of Experiment 1 and to rule out various alternative explanations for the superiority of silent letters in the recall task. Because two different sets of words were used in Experiment 1, we worried that properties specific to these words may have made one set harder to judge but easier to recall. To eliminate this possibility, the set of words was held constant in Experiment 2. Half of the subjects judged silent letters in the words, and half judged pronounced letters. Then both groups were surprised with the letter-prompted word recall task. Experiment 3 was performed to rule out letter location as a factor, since the words used in Experiment 2 displayed many of the silent letters in positions later than those of the pronounced letters, possibly causing subjects to scan the images of words more completely for silent letters. Experiments 4 and 5 were conducted to determine whether silent-letter recall was superior because subjects were taking more time to judge silent letters. Also, at the end of Experiment 5, subjects were questioned about their perception of the tasks, in order to determine whether silent-letter performance was boosted because subjects had been selectively attending to silent letters during the tasks.

\section{EXPERIMENT 2}

\section{Method}

Subjects. The subjects were 12 second-graders and 26 thirdgraders, 18 males and 20 females, with mean age of 102 months. They were tested individually in the spring. Third-graders were recruited when it became apparent that second-graders were unfamiliar with some of our printed words.

Materials. Selected as targets were 10 common words that included silent letters in their spellings. For each, two noninitial letters were selected: one silent and one pronounced. These are listed in Table 2. Absent letters were not included for judgment in this experiment.

Procedures. The sequence of tasks was the same as in Experiment 1: reading the target words, completing the IRAS, 
Table 2

List of Words and Letter Prompts in Experiment 2 and Number of Subjects Recalling Each Word

\begin{tabular}{|c|c|c|c|c|c|}
\hline \multirow[b]{2}{*}{ Word } & \multicolumn{2}{|c|}{ Silent } & \multicolumn{2}{|c|}{ Pronounced } & \multirow{2}{*}{$\begin{array}{c}\text { Differ } \\
\text { ence }\end{array}$} \\
\hline & Letter & Recall & Letter & Recall & \\
\hline school & $\mathrm{h}$ & 14 & c & 17 & -3 \\
\hline straw & w & 10 & $t$ & 5 & 5 \\
\hline wide & e & 15 & i & 9 & 6 \\
\hline laugh & $\mathbf{u}$ & 7 & a & 5 & 2 \\
\hline listen & $\mathrm{t}$ & 14 & $\mathrm{~s}$ & 4 & 10 \\
\hline friend & i & 9 & $\mathrm{n}$ & 10 & -1 \\
\hline dead & a & 12 & $\mathrm{e}$ & 10 & 2 \\
\hline young & 0 & 13 & $\mathbf{u}$ & 9 & 4 \\
\hline comb & $\mathrm{b}$ & 18 & $\mathrm{~m}$ & 12 & 6 \\
\hline bright & $\mathrm{g}$ & 14 & $r$ & 13 & 1 \\
\hline Mean & & 12.6 & & 9.4 & +3.2 \\
\hline
\end{tabular}

Note-Maximum number $=19$.

imagining words and judging letters, and recalling words associated with letters. For half of the subjects, the letter was always pronounced. For the other half, the letter was always silent. All second-graders and nine pairs of third-graders were given two letter-judgment trials. Four pairs of third-graders judged letters only once.

Subjects within each grade were matched according to scores on the IRAS tests. As children were tested, each child was assigned to one of the two conditions. The first member of a pair was assigned randomly. When a second child with similar scores came along, he/she was yoked with the first and assigned to the other condition.

\section{Results}

Children were familiar with most of the target words. The mean numbers of words correctly read on the first word recognition trial were 8.1 words for second-graders and 9.8 words for third-graders (maximum $=10)$. In the letter-judgment task, children performed almost perfectly, recognizing a mean of 9.8 pronounced letters and 9.4 silent letters correctly. The difference was not statistically significant $[t(18)=1.27, p>.05]$. It may be that ceiling effects precluded detection of the difference favoring pronounced letters apparent in Experiment 1. Also, since there were no absent letters eliciting negative judgments in this task, subjects may have been responding positively to letters they were doubtful about.

In the recall task, the mean number of words prompted by silent letters was again superior, 6.6 words, as contrasted to 4.9 words prompted by pronounced letters (maximum $=10$ words). A matched-pair $t$ test confirmed that this difference was significant $[t(18)=$ $2.51, p<.05]$. These findings replicate the pattem found in the previous experiment.

Comparison of third-graders given one and two letter-judgment trials prior to the recall task revealed that the recall pattern favoring silent letters was apparent for both groups and that the benefit of having judged letters twice prior to recalling them was equivalent across letter types (i.e., mean advantage $=2.85$ for silent letters and 2.90 for pronounced letters). This indicates that letter-judgment practice neither magnified nor diminished silent-letter effects.
To further verify the superiority of silent letters as recall prompts, results were checked across words as well as across subjects. Recall values are reported in Table 2. Comparison of recall for silent and pronounced letters revealed that the pattern favoring silent letters held for 8 of 10 words. Thus, results appear to generalize across words as well as across subjects.

It was not the case that pronounced letters elicited more word intrusions. Inspection of the number of errors in which subjects matched the wrong words to letters revealed about the same numbers for pronounced and silent letters (i.e., 23 vs. 26 , respectively). Thus, greater response interference does not account for the poorer recall with pronounced letters. The greater number of errors in the pronounced condition entailed mainly nonresponses (i.e., 68 among pronounced subjects vs. 37 among silent subjects). Extralist intrusions were rare (i.e., five in the pronounced condition, one in the silent condition).

Comparison of the locations of letters in words revealed that silent letters occurred in later positions than pronounced letters in 8 of 10 cases. $^{1}$ (The exceptions were "friend" and "young.") Furthermore, whereas three of the silent letters were in final positions, none of the pronounced letters was final. It may be that subjects scanned more of the orthographic image to locate silent than pronounced letters and that words whose images were more completely processed were better remembered. A third experiment was conducted to check on this explanation.

In selecting subjects for the present experiment, we had to reject a number of second-graders because they were unfamiliar with our target words (i.e., $42 \%$ misread at least two words). This was less true of third-graders (i.e., 7\% misread two or more words). To maximize chances that subjects tested in the next experiment would have all the target words stored in memory, we sampled first-term fourth-graders.

\section{EXPERIMENT 3}

\section{Method}

Subjects. The subjects were 28 fourth-graders enrolled in a parochial school, 13 males and 15 females, with mean age of 113.6 months (9.5 years). Subjects were tested individually in the fall.

Materials. For the letter-judgment recall task, six pairs of words were formed such that members of each pair contained the same target letter in the same position, the letter being pronounced in one word and silent in its mate. Pair members were very similar in their frequency of occurrence (Thorndike \& Lorge, 1944) and were identical in letter length. The pairs are listed in Table 3. All target letters were consonants. Mixed in with each set of words were six filler words, each paired with a consonant target letter not present in the spelling and not one of the silent-pronounced target letters. The order of words differed across tasks and was quasi-random (i.e., no more than two words in the letter-present or letter-absent category appeared in succession).

Procedures. The three tasks (i.e., reading words, judging letters, and recalling words associated with letters) were conducted as in Experiment 2. All subjects were given two wordreading trials and only one trial to judge letters. Following 
Table 3

List of Words and Letter Prompts in Experiment 3 and Number of Subjects Recalling Each Word

\begin{tabular}{|c|c|c|c|c|c|}
\hline \multicolumn{2}{|c|}{ Word Pair } & \multirow{2}{*}{$\begin{array}{l}\text { Target } \\
\text { Letter }\end{array}$} & \multicolumn{2}{|c|}{ Recall } & \multirow[b]{2}{*}{ Difference } \\
\hline Silent & Pronounced & & Silent & Pronounced & \\
\hline sword & swing & W & 3 & 3 & 0 \\
\hline comb & curb & $\mathrm{B}$ & 12 & 3 & 9 \\
\hline scissors & scribble & $\mathrm{C}$ & 7 & 4 & 3 \\
\hline honest & handle & $\mathrm{H}$ & 8 & 5 & 3 \\
\hline walk & wild & $\mathbf{L}$ & 6 & 5 & 1 \\
\hline island & escape & S & 5 & 5 & 0 \\
\hline Mean & & & 6.83 & 4.17 & +2.7 \\
\hline
\end{tabular}

Note-Maximum number $=14$.

the recall task, knowledge of the spellings of words in the silent and pronounced sets was tested by having subjects write each word after it was pronounced.

A group administered spelling task (subtest of the Durrell Analysis of Reading Difficulty test) was given in the subjects' classroom by the experimenter to measure general spelling ability. Scores on the spelling test were used to form matched pairs of subjects prior to the experiment. Ten pairs of scores were identical. Four differed by one point. In half of these pairs, the higher scoring member was assigned to the silentletter condition; in the other half, he/she was assigned to the pronounced-letter condition.

\section{Results}

Subjects were able to read and to judge letters almost perfectly. The few errors occurred mainly with silentletter words. In the spelling test, although target letters were included in most of the spellings, the words in the silent set were misspelled more often than those in the pronounced set (e.g., 18 vs. 8 misspellings). These results are consistent with those above, indicating that words containing silent letters are somewhat harder to store in memory.

In the recall task, to determine whether silent letters prompted better recall of words than pronounced letters did, recall scores for the pairs of subjects were analyzed with matched-pair $t$ tests. Results confirmed that silent-letter subjects outperformed their pronouncedletter mates $[\mathrm{t}(13)=3.02, \mathrm{p}<.01$ (two-tailed test)] The mean number of words recalled was 2.93 for the silent-letter group and 1.79 for the pronounced-letter group (maximum $=6$ ).

To verify the silent-letter pattern across word pairs, recall for the words was tallied. Results are reported in Table 3, in which it is evident that silent letters prompted better recall than pronounced letters for four of six word pairs. In no case was the pattern reversed.

In conclusion, these results confirm previous findings. They show that the greater salience of silent letters in Experiment 2 did not arise because silent letters occupied later positions in words. In the present study, letter position remained constant, yet silent letters still prompted better recall of words than pronounced letters did.

\section{EXPERIMENT 4}

Another reason why silent-letter words may have been easier to recall is that subjects took more time to judge these letters than pronounced letters in the wordimagining task. Being silent, the letters may have been harder to find in memory. Such an effect might be predicted by Craik and Lockhart's (1972) levels-ofprocessing theory, which suggests that stimuli that are processed to a deeper level are more easily recalled. A fourth experiment was conducted to test this hypothesis.

The letter-judgment recall task was modified slightly to permit measurement of response latencies in judging letters. Subjects were told to imagine the spelling of each of several words. As soon as they reported "seeing" the spelling, a letter was flashed on a screen, and the time required to decide whether it was present or absent in the word was measured with a voice-activated relay attached to a timer. At the end of the task, subjects' memory for silent and pronounced letters was tested to verify the greater recallability of silent letters.

Some other letter contrasts were included as well, to compare judgment latencies: letters appearing toward the beginnings vs. endings of word spellings, letters printed in lower-vs. uppercase, and absent letters that were plausible vs. implausible sound symbols for elements of word pronunciations. We reasoned that if letter position was involved in the silent-letter effect, then early-occurring letters should be judged faster than lateoccurring letters. If the most commonly viewed form of spellings is stored in memory, then letters printed in lowercase on the screen might take less time to judge than letters in uppercase. In order to assess whether pronunciation was playing any role in this visual letterjudgment task, we included two types of absent letters eliciting negative judgments, one symbolizing plausible sounds in words (e.g., $U$ in "shoe") and one lacking any correlate in sound (e.g., U in "ship"). We reasoned that if subjects are simply consulting imagined spellings and ignoring pronunciations, then neither letter type should take longer to reject. However, if sound has some influence, then plausible-letter symbols should take more time. 


\section{Method}

Subjects. The subjects were 12 female and 6 male fourthgraders tested individually in the fall (mean age $=114$ months). All but two of the subjects were reading above grade level as measured on the Slosson Oral Reading test. Good readers were employed to insure that subjects would be familiar with the printed forms of words we had chosen for this task.

Materials. Selected for judgment were eight practice words and 40 pairs of target words: 14 pairs in the silent vs. pronounced comparison set, 8 in the lower-vs. uppercase set, 4 in the early vs. late set, and 14 in the plausible vs. implausible absent-letter set. Pair members had the same number of letters and similar orthographic structures. Letters selected for judgment were in the same position, except in the early vs. late set, and were similar if not identical within pairs. Uppercase letters selected for judgment were ones that differed in shape from their lowercase mates. The target words and letters in the silentpronounced and plausible implausible sets are listed in Table 4. The 40 pairs were distributed across four blocks of 20 words each. Pair members were divided so that one member appeared in the first or second block and the other in the third or fourth block. The order of presentation of letter-contrast types was counterbalanced (e.g., half of the silent letters preceded their pronounced mates and half followed their mates). Within each block, the letters were ordered randomly. Different orders were employed in the word-reading, letter-judgment, and recall tasks.

Each target letter was typed and photographed. The slides were projected onto a rear-view screen by a Carousel projector. Advancement of the slide started a digital timer that was stopped by a voice-activated relay in response to the subject's vocalized decision, "yes" or "no."

Procedures. First subjects were shown the target words each printed on a card in a binder. They read the words twice. The experimenter corrected their errors, and on Trial 1 she read a sentence illustrating each word's meaning. Three of the target words were homonyms (i.e., would, hour, hear), so subjects were asked to generate sentences for them on Trial 2 to verify that they knew the appropriate meanings for those spellings.

The letter-judgment task came next. Subjects were shown a card with a horizontal line (1.5 in. long) centered .625 in. beneath a box (.375 in. square). They were told to imagine the word "car" written out on the line, and then a card with "car" printed on the line (lowercase letters) was shown to illustrate how the word should look. Next, they were told to imagine their name on the blank line and to decide whether it contained particular letters named by the experimenter (two present, two absent). Next, they were introduced to the equipment. Procedures were practiced with eight words followed by the target words. Children faced a screen $2.5 \mathrm{ft}$ away. For each word, a slide displaying the horizontal line and box was presented. The experimenter pronounced the word and told children to imagine what it looked like written out on the line and to tell her when they could "see" it. Then they were told to look at the box because the letter to be judged would appear on the next slide in this location on the screen. When the target letter appeared (visual angle $=2.5 \mathrm{deg}$ ), they vocalized their decision. They were told to respond rapidly yet accurately. (Everyone responded within $5 \mathrm{sec}$.) For the three homonyms, the experimenter reminded subjects of the meanings before they imagined the spellings. Subjects were given half of the words (Blocks 1 and 2) to judge on Day 1 and half (Blocks 3 and 4) to judge on a 2nd day.

At the end of the letter-judgment task each day, subjects were shown the 14 words in the silent-pronounced comparison set presented that day and asked to recall which letters they had judged for each word.

\section{Results}

Letter-judgment response times were analyzed separately for each contrast set. Since there were so few word pairs in the early vs. late comparison set, eight additional word pairs were recruited by forming new combinations from among the words used in the other comparison sets. Pair members had the same number of letters, and target letters were equidistant from the ends of the words.

Subjects were quite familiar with the target words and letters. The mean number of words read correctly on Trial 1 of the word identification task was 78.5 (80 maximum). The mean number of letters judged correctly was 75.2 ( 80 maximum). The equipment worked properly and yielded valid reaction times (RTs) on $98 \%$ of the responses.

Although most of the letters were judged correctly, significantly more errors occurred with silent than with pronounced letters [mean $=2.3$ vs. .6 errors, 14 maximum; $t(17)=5.49, \mathrm{p}<.01$ (two-tailed test)]. Also,

Table 4

List of Target Letters and Word Pairs in Experiment 4 and Percentages of Judgments Displaying Shorter RTs to Silent and Implausible Members of Pairs

\begin{tabular}{|c|c|c|c|c|c|c|}
\hline Silent & $\begin{array}{c}\text { Peicent } \\
\text { Silent }\end{array}$ & Pronounced & Implausible & $\begin{array}{c}\text { Percent } \\
\text { Implausible }\end{array}$ & Plausible & $\begin{array}{l}\text { Target } \\
\text { Letter }\end{array}$ \\
\hline iSland & 81 & iNsect & telescope & 88 & telephone & $\mathrm{f}$ \\
\hline Wrong & 77 & World & maybe & 83 & magic & $\mathrm{j}$ \\
\hline whisTle & 69 & freckle & ship & 81 & shoe & $\mathbf{u}$ \\
\hline siGn & 69 & siZe & buffalo & 77 & bicycle & $\mathbf{s}$ \\
\hline $\operatorname{com} \mathbf{B}$ & 67 & cluB & twist & 67 & twice & $y$ \\
\hline musCle & 63 & rasCal & boy & 67 & box & s \\
\hline draW & 60 & drip & songs & 67 & socks & $\mathrm{x}$ \\
\hline Hour & 57 & Hear & ears & 63 & eyes & $\mathrm{i}$ \\
\hline autumN & 57 & AugusT & wagon & 44 & water & $d$ \\
\hline gHost & 53 & gRunt & dream & 41 & dance & $\mathrm{t}$ \\
\hline Knee & 53 & Keep & rest & 38 & raft & $v$ \\
\hline rasPberry & 50 & susPected & north & 38 & nurse & $\mathrm{c}$ \\
\hline lauGh & 33 & larGe & chain & 38 & chair & $\mathrm{e}$ \\
\hline lisTen & 8 & masTer & speed & 33 & spoon & $\mathbf{u}$ \\
\hline Mean & 57 & & & 59 & & \\
\hline
\end{tabular}

Note-For silent-pronounced pairs, the target letter is capitalized in boldface type. 
plausible-sounding absent letters tended to be judged incorrectly more often than implausible letters, although errors were few and the difference fell short of significance $[$ mean $=.83$ vs. $.11,14$ maximum; $t(17)=2.00$, $.05<\mathrm{p}<.10$ (two-tailed test)]. Very few errors occurred in the other letter categories, and differences were not significant $(\mathrm{p}>.10)$.

Because we were interested in letter-judgment latencies for words whose printed forms were familiar to subjects, we considered only RTs to word pairs whose members were successfully read by subjects on Trial 1 of the word-identification task and whose letters were judged correctly as present or absent. For each successfully performed word pair, the difference in RT was calculated. Within each of the four letter-contrast sets, the median RT difference was identified for each subject. Because the resulting distributions of median values across subjects were skewed (i.e., as long as $34 \mathrm{sec}$ were taken for letter judgments in some instances), sign tests were used to determine whether the signs of the median differences were predominantly positive or negative across subjects for each contrast set.

Results revealed that in the pronounced-vs. silentletter comparison, contrary to expectations, median RTs to silent letters were shorter than median RTs to pronounced letters for 15 of 18 subjects. The probability of this happening by chance is $p=.004$. In the comparison of plausible- and implausible-sounding absent letters, median RTs to plausible letters were longer than median RTs to implausible letters for 15 of 18 subjects, indicating that plausible letters took longer to reject than implausible letters $(\mathrm{p}=.004)$.

RT differences were examined across word pairs as well as across subjects within each contrast set. Only correct letter judgments to successfully read word pairs were considered, as before. In the case of pronounced vs. silent letters, there were 11 of 14 word pairs in which the majority of subjects responded more quickly to silent than to pronounced letters $(p=.029)$. The proportion of subjects displaying shorter RTs to silent letters is listed for each word pair in Table 4. This reveals that the silent-letter advantage generalized across word pairs as well as across subjects.

One explanation for the faster silent-letter judgments is that the procedure of considering RTs only for word pairs that were read and judged accurately may have eliminated more hard-to-judge silent than pronounced letters from the analysis and thus biased the data toward easier silent-letter judgments. To check on this possibility, the invalid pairs were examined. Results revealed that $32 \%$ of the RTs to the set of silent-pronounced word pairs had to be eliminated because of inaccurate responding to one or both members of a pair. Silent letter problems were found to account for the majority of the pairs being dropped (62\%). Pronounced-letter problems eliminated $23 \%$. Errors on both letters accounted for the remainder (15\%). To determine whether this biased performance, we examined whether the number of pairs eliminated because of silent-letter problems was correlated with the proportion of valid pairs exhibiting faster RTs to silent letters. Correlations across words and across subjects were not significantly different from zero ( $p>.05$ ). For subjects, $r=.12$, and for word, $r=-.35$, indicating the opposite relationship (i.e., word pairs with a greater number of RTs invalidated by silent-letter problems tended to exhibit a smaller, not a larger silent-letter advantage). This suggests that silent-letter effects did not result from the selective elimination of hard-to-judge silent letters from the RT analysis.

In the analysis of the plausible-implausible contrast across words, only 8 of 14 pairs revealed the pattern evident in the subjects analysis, that is, longer RTs for plausible letters $(p>.05)$. Proportions are listed for each word pair in Table 4. (Note that values represent proportions of shorter RTs to implausible letters.) From an inspection of the pairs, it becomes apparent that some of the plausible-sounding letters may have been better instances than others. Those that were more effective in delaying RTs (top of the list in Table 4) were ones for which the plausible sound symbolized by the letter was especially obvious in the word's pronunciation, for example, when the entire name of the letter could be detected (i.e., F named "ef," telephone; U named "yue," shoe; Y named "wie," twice; I, eyes). In contrast, the sounds of letters failing to reveal the pattern were much less obviously embedded in pronunciations, for example, $\mathrm{T}$ in dance (rhyme of pants), $D$ in water, $V$ in raft. ( $D$ and $V$ symbolize voiced mates of the voiceless sounds symbolized by $T$ and $F$, respectively). The correspondence between these letters and sounds in pronunciations may not have been perceived, and so subjects may have been able to reject them more quickly. Since RTs favored implausible letters across subjects and also across the majority of word pairs appearing to be good instances of the contrast, it is concluded that this contrast does affect performance, that it takes subjects longer to judge and reject plausiblethan implausible-sounding letters.

Although nonparametric tests revealed significant differences in RTs favoring shorter silent-letter judgments across subjects and across words, when we compared the means of subjects' median RTs for silent and pronounced letters (only valid pairs considered), the values were very close (silent mean $=2.06 \mathrm{sec}$ vs. pronounced mean $=2.09 \mathrm{sec}$ ). To understand why this might be, we plotted frequency distributions of RTs to all valid pairs of words. The two histograms are shown in Figure 1. It is apparent that the frequency of especially short latencies for silent letters was greater than that for pronounced letters, but there were also slightly more long silent-letter RTs as well. From this, we conclude that mean values failed to represent the difference accurately, since the distributions were skewed rather than normal, with a clustering of short-latencies and another 


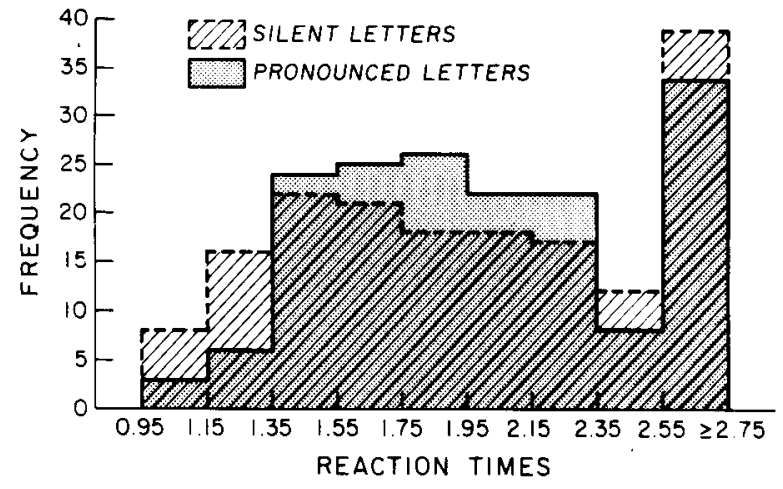

Figure 1. Histogram of reaction times in seconds to judge silent and pronounced letters in Experiment 4.

clustering of prolonged latencies. Apparently, a difference favoring silent letters emerges when RTs are short, presumably when the printed words are well established in memory. Among less familiar words, silent-letter judgments may not be more rapid than pronounced-letter judgments. Consistent with this, we found that silent letters were judged less accurately than pronounced letters.

Following the letter-judgment task, subjects were shown each of the words in the pronounced-silent set presented that day and asked to recall which letter they had judged for that word. Results revealed that silent letters were recalled significantly better than pronounced letters $[$ mean $=11.2$ vs. 8.9 correct, maximum $=14$; $t(17)=4.50, p<.01]$. A difference favoring silent letters was statistically significant also when recall was analyzed separately for each of the 2 days $(p<.05)$. This shows that the difference was not specific to Day 2 after subjects had been alerted about the recall test. Thus in a task differing from that used in Experiments 1-3, one in which letters were recalled for words rather than words for letters, the same advantage favoring silent letters was detected.

In the analyses of early-late and lowercase-uppercase letters, no RT patterns favoring one or the other letter categories were apparent across subjects or across word pairs ( $p>.05)$. However, the comments of one subject offered some support for the hypothesis that the ortho. graphic images being consulted were in lowercase letters. After judging accurately each of two capital letters, a boy spontaneously commented, "but the one in there [his image] isn't a capital." It may be that the letterjudgment RT measure was not sufficiently sensitive to the upper- vs. lowercase manipulation, making results inconclusive on this question.

\section{EXPERIMENT 5}

A final experiment was conducted to replicate the finding in Experiment 4 that silent letters were detected more rapidly than pronounced letters. Some additional concerns were also addressed. Silent letters may have been judged more rapidly because subjects became aware of them and began picking them out during the letter-judgment task. To check on this, children were queried about their perception of the task at the end. Another factor of concern was the difference in phonological complexity of silent- and pronounced-letter words employed in Experiment 4. Because we attempted to equate the number of letters in spellings of paired words, pronounced-letter words often had one more phoneme than words with silent letters (i.e., three in comb vs. four in club). It may be that subjects took longer to find and judge pronounced letters because there were more phonemes to scan in these words. Corcoran (1966, 1967) and Hatch et al. (1974) have proposed acoustic scanning as a process operating when spellings are inspected for letters. Some evidence for acoustic scanning was uncovered in Experiment 4, in which plausible-sounding absent letters were found to take longer to reject than implausible letters. To determine whether phoneme length was responsible for RT differences favoring silent letters, several word pairs were equated for phoneme length in Experiment 5.

\section{Method}

Subjects. The subjects were 12 female and 10 male fourthgraders, with mean age of 114 months (9.5 years), tested individually in the fall. All were native English speakers. Subjects were selected from a larger pool of 37 fourth-graders who were also tested. Twelve were excluded because they lacked familiarity with a sufficient number of target word spellings (i.e., over $33 \%$ of their RTs to the silent-pronounced word pairs were invalid).

Materials. Selected for judgment were 18 pairs of words in the silent-pronounced contrast set, 12 filler words to be judged as lacking target letters, and 3 practice words. The silentpronounced word pairs are listed in Table 5, along with the properties that were shared by pair members. The letter judged was the same for $78 \%$ of the pairs, the position of the letter was identical for $100 \%$, the number of phonemes was the same for $61 \%$, and the number of letters in spellings was the same for $89 \%$. The 18 pairs were distributed across three blocks. Each block also included four absent-letter words to insure that "No," as well as "Yes," was a valid response. None of the absent letters corresponded to sounds in pronunciations: $R$, basket; $T$, school; $\mathbf{F}$, telescope; J, maybe; $\mathrm{V}$, animal; $A$, picture; $Z$, even; $N$, turkey; $D$, forget; $M$, enough ; $P$, money; $X$, songs.

Ordering of words within blocks was quasi-random. Pair members were always separated by at least four words. Order of presentation was counterbalanced so that half of the silentletter words preceded and half followed their pronounced mates. No more than two letters in the same category (silent, pronounced, and absent) were judged in succession. Blocks were preserved in ordering words across the three tasks (i.e., reading the words, judging letters, and recalling letters in words), but word order within blocks was varied. All of the letters presented for judgment were printed in lowercase, except $L$ and $Y$, which were capitalized. This was because lowercase $L$ is sometimes mistaken as the digit one and $Y$ was the mate to $L$ in one of the silent-pronounced pairs.

Procedures. First, subjects read all 51 words twice, the first time presented on the screen and the second time on cards in a binder. Errors were corrected. A sentence illustrating each word's meaning was read on Trial 1. 
Table 5

List of Target Letters and Word Pairs in Experiment 5 and Percentages of Responses Favoring Silent Letters (\%S)

\begin{tabular}{|c|c|c|c|c|}
\hline \multicolumn{2}{|c|}{ Word Pair } & \multirow{2}{*}{$\begin{array}{c}\text { Properties } \\
\text { Identical }\end{array}$} & \multicolumn{2}{|c|}{$\% \mathrm{~S}$} \\
\hline \multirow[t]{2}{*}{ Silent } & \multirow[t]{2}{*}{ Pronounced } & & \multirow[t]{2}{*}{ Latency } & \multirow[t]{2}{*}{ Recall } \\
\hline & & Block 1 & & \\
\hline Knife & Kind & \multirow{2}{*}{$\begin{array}{l}\mathrm{L} \\
\mathrm{Lh}\end{array}$} & $37^{*}$ & 100 \\
\hline hEart & hElp & & 56 & 86 \\
\hline colum $N$ & vacuuM & \multirow{2}{*}{$\begin{array}{l}\text { Ph Sp } \\
\text { Ph Sp }\end{array}$} & 67 & 67 \\
\hline beYond & belong & & 60 & 94 \\
\hline peOple & brOken & $\mathrm{Sp}$ & 61 & 100 \\
\hline fruIt & strIp & $S p$ & 61 & 80 \\
\hline \multicolumn{5}{|c|}{ Block 2} \\
\hline whisTle & whisPer & $\mathrm{Sp}$ & 69 & 83 \\
\hline siGn & $\mathrm{caGe}$ & L Ph Sp & $42 *$ & 100 \\
\hline Wrong & World & $\mathrm{Sp}$ & 55 & 100 \\
\hline gHost & cHest & $\mathrm{L} P \mathrm{Ph} \mathrm{Sp}$ & 100 & 73 \\
\hline $\operatorname{climB}$ & clouD & $\mathrm{Ph} \mathrm{Sp}$ & 72 & 100 \\
\hline sCissors & sCribble & $\mathrm{L} P \mathrm{Ph} \mathrm{Sp}$ & 76 & 89 \\
\hline \multicolumn{5}{|c|}{ Block 3} \\
\hline bUild & bUnch & $\mathrm{L} P h \mathrm{Sp}$ & 53 & 82 \\
\hline $\operatorname{com} B$ & curB & $\mathrm{Sp}$ & 60 & 80 \\
\hline waLk & saLt & $\mathrm{Sp}$ & $29 *$ & 67 \\
\hline Honest & Handle & $\mathrm{L} \mathrm{Ph} \mathrm{Sp}$ & 63 & 100 \\
\hline sWord & sWing & $\mathrm{L} P \mathrm{Ph} \mathrm{Sp}$ & 82 & 63 \\
\hline iSland & eScape & $\mathrm{L} \mathrm{Ph} \mathrm{Sp}$ & $50^{*}$ & 91 \\
\hline Mean & & & 61 & 86 \\
\hline
\end{tabular}

Note-For silent-pronounced pairs, the target letter is capitalized in boldface type. Properties identical for words: $L=$ same target letter; $P h=$ same number of phonemes; $S p=$ same number of letters in spelling. Proportions (\%S) for recall reflect the number of times subjects recalled only one of the two letters for a pair divided into the number of times the single letter was the silent member of the pair. $\quad{ }^{*}$ Exceptions to the pattern of shorter latencies for silent letters.

The letter-judgment task followed. Procedures here were the same as in Experiment 4, except that no homonyms were distinguished and the entire task was completed in 1 day. Also, prior to reading the words, subjects were shown and named all 26 alphabet letters to familiarize them with the type font used in the letter-judgment task.

The letter recall task was presented on slides rather than cards so that latencies to retrieve the letters could be determined Subjects were shown each of the 36 words from the silentpronounced set and were given $10 \mathrm{sec}$ to recall the letters.

At the end of the session, subjects were asked several questions about their perceptions and strategies in the tasks. The questions of central interest for determining whether subjects were picking out silent letters as they were imagining spellings were "When you were imagining the spellings, what went on in your mind? How did you do it? What did you think about?" Also, they were asked what made it easy or hard to judge letters and to recall the letters.

\section{Results}

Subjects were able to read most of the words and to judge most letters accurately in the silent-pronounced set, although slightly more errors were made with silentthan with pronounced-letter words: reading words $1 \%$ vs. $.2 \%$ errors, judging letters $4 \%$ vs. $1 \%$ errors, respectively. A few letter-judgment latencies were invalidated by equipment failures $(2.8 \%)$ and by subjects stopping the timer by extraneous noises or self-corrections or failing to attend (3.7\%).

RTs to judge silent and pronounced letters were considered valid only if judgments were accurate for both members of a word pair and if the words were read accurately on Trial 1 . The number of valid pairs (79\% of total) ranged from 12 to 16 (maximum $=18$ ) across subjects. For each subject, differences in RT were calculated for all valid pairs and the median difference was determined. The sign of the median difference favored silent letters (shorter latencies) for 19 of 22 subjects. A matched-pair $t$ test confirmed that this difference was significant $[\mathrm{t}(21)=3.41, \mathrm{p}<.01$ (two-tailed test) $]$. RTs examined across word pairs revealed the same pattern, favoring silent letters in 14 of 18 pairs. The percentage of subjects displaying shorter RTs to silent letters for each word pair is given in Table 5 . The probability of this occurring by chance is $p=.015$. From Table 5 , it is apparent that whether the phonemic structure of word mates was identical or not made little difference. This discounts the hypothesis that longer phonemic scans with pronounced-letter words accounted for RT differences in Experiment 4.

To verify that stimulus-selection factors arising from the elimination of invalid pairs did not bias the data sample in favor of easier silent-letter judgments, correlation coefficients were calculated between the number of pairs eliminated by silent-letter errors and the proportion of valid pairs exhibiting shorter RTs to silent letters. As in Experiment 4, the correlations were low and nonsignificant across both words and subjects $(p>.05)$.

In recalling the letters, every single subject identified more silent than pronounced letters accurately [mean $($ silent $)=14.4$ vs. mean $($ pronounced $)=7.3,(\operatorname{maxi}-$ mum $=18)]$. This pattern was replicated across word pairs as well. In half of the recall attempts, only one of the two letters was remembered. The proportion of times this was the silent letter is given for each pair in Table 5 . The silent letter is favored in every case. In order to determine whether RTs to recall silent letters were shorter, the difference between silent and pronounced latencies was calculated for cases in which there were valid RTs to both words. (RTs were invalidated by equipment failures, by subject errors or false starts, and by inaccurate responses in earlier tasks.) There were 16 subjects with valid RTs to recall letters for at least three pairs. The sign of the median difference favored silent letters for 13 of these subjects $(p=.011)$. This pattern held across words as well. Of the 13 words with three or more valid RT differences, the signs of 11 favored shorter RTs to silent letters $(p=.011)$. This reveals that silent letters were recalled more quickly, as well as more accurately, than pronounced letters.

In the letter-judgment task, the words were presented in three blocks. Of interest was whether response patterns favoring silent letters might be apparent primarily on later-occurring blocks, indicating that silent-letter awareness in tasks was responsible for the phenomenon. 
Inspection of Table 5 yields no evidence for this. The mean proportions of RTs favoring silent letters were: Block $1=57 \%, 2=69 \%, 3=56 \%$. Although the middle block was slightly higher, the first and last blocks were equivalent.

Posttest interviews were conducted to elicit descriptions of any strategies subjects used during the tasks. Of interest was whether subjects might report that they anticipated silent letters in the letter-judgment task or that they simply picked out silent letters when shown word spellings in the recall task. Analysis of interview protocols revealed that subjects' answers fell in to three groups: (1) subjects $(\mathrm{N}=6)$ who mentioned use of a strategy involving silent letters in one or both tasks (for example, one subject asserted, "I knew what you were going to ask me about before you even asked it because it was silent"); $(2)$ subjects $(\mathrm{N}=6)$ who mentioned that some of the letters were silent but who did not report making use of this information in the tasks (rather, their comments about silent letters pertained to the difficulty of detecting or remembering them, since they could not be heard in the words); (3) subjects $(\mathrm{N}=10)$ who mentioned nothing about the pronounceability of letters (these subjects tended to report that they did not know how they performed the tasks).

Although the three groups clearly differed in their perception of the tasks, comparison of their performances revealed that silent-letter effects were not limited to subjects who expressed awareness of silent letters. Comparison of groups in the letter-judgment task revealed similar mean proportions of word pairs with shorter RTs to silent letters: strategy group (Group 1 above $)=.59$, silent-letter-mentioned group $($ Group 2$)=$ .66 , no-awareness group (Group 3$)=.60$. There were three subjects who failed to exhibit median RT differences favoring silent letters, and surprisingly, two of these fell in the strategy group and the other in the no-awareness group. This suggests that awareness provided little advantage in judging letters and may have even interfered in a couple cases. In the letter recall task, the mean numbers of silent letters recalled by the groups were: strategy $=16.2$, mention $=14.0$, and no awareness $=13.5$ correct $($ maximum $=18)$; all of these means were clearly above the mean for pronounced-letter recall ( 7.3 letters). This shows that although strategy subjects may have recognized more of the silent letters, all three groups exhibited the basic effect, superior recall of silent letters. Silent-letter awareness strategies may have helped subjects in this recall task. However, it is unlikely to have helped in the recall task used in Experiments 1.3, since the earlier task was harder and required recall of words associated with letters rather than simply recognition of letters in words. In conclusion, although it was the case that silent letters caught the attention of some subjects, this factor does not appear to be responsible for the salience of silent letters observed in the present studies.
There were 12 subjects who were tested but excluded from the sample because errors were excessive. Median differences in RT to judge silent and pronounced letters were calculated for these subjects. Interestingly, only a slight majority displayed shorter RTs to silent letters: $58 \%$ here vs. $86 \%$ in the good-reader sample. In the letter recall task, the mean number recalled was lower than in the above sample, particularly for silent letters $[$ mean (silent) $=9.4$ here vs. 14.4 above; mean (pronounced) $=6.7$ here vs. 7.3 above] . Analysis of interview responses revealed that no subjects mentioned use of a silent-letter strategy, and only 3 of the 12 mentioned the distinction between silent and pronounced letters. Interestingly, of the three subjects noticing silent letters, two failed to reveal a silent-letter RT advantage; however, all three identified several more silent than pronounced letters in the recall task. This fits in with the above data, indicating that silent-letter awareness may have facilitated performance more in the recall task than in the letter-judgment task. These results suggest that poorer readers/spellers may distinguish silent letters, but not to the extent that good spellers do.

\section{DISCUSSION}

Results of the present study yield evidence for the distinction between silent and pronounced letters in children's knowledge of word spellings. Pronounced letters were recognized somewhat more accurately than silent letters were. However, silent letters were detected more rapidly and prompted better recall of the words previously judged than pronounced letters did. Several alternative explanations for these effects were considered but discounted in one or another experiment. The possibility that the silent-letter words were more memorable than the pronounced-letter words was ruled out in Experiment 2, in which the same set of words was recalled in response to silent- and pronounced-letter prompts. The possibility that differences in letter position accounted for results was ruled out in Experiment 3, in which silent and pronounced letters occupied the same positions. Also, Experiment 4 showed position to be unimportant to the speed of judging letters. The possibility that subjects recalled silent-letter words better because they spent more time and effort locating the silent letters in memory was ruled out in Experiments 4 and 5, which showed that subjects in fact took less time to locate silent letters than to locate pronounced letters. The possibility that subjects' RTs to silent letters were shorter because these words had fewer phonemes and, hence, could be scanned more quickly than pronounced-letter words was rejected in Experiment 5, in which RTs were shorter even when phoneme length was equated. The possibility that superior performance with silent letters resulted because subjects began to notice, pick out, or anticipate silent 
letters was ruled out by findings in Experiment 5, which showed that silent-letter effects were just as clear-cut among subjects who expressed no awareness of the fact that some of the letters were silent as among subjects who reported noticing this property of letters. The possibility that the sample of valid RTs was biased to favor easier silent-letter judgments was rejected in Experiments 4 and 5 by data indicating that silentletter effects were not larger for subjects or word pairs for which more RTs were invalidated by silent-letter errors.

An interpretation that makes findings compatible with our theory of printed-word learning ascribes silentletter effects to processes that were operative at the time the spellings were stored in memory. According to the theory, orthographic representations enter memory when letters are grounded in sounds detected in the word's pronunciation. Because silent letters are singular exceptions to this grapheme-phoneme letter-acquisition principle, they are not stored as readily as pronounced letters. When they do gain entrance into memory, their status as exceptions leaves a mark, making them especially salient in the orthographic representation. Such a marking operation would explain why silent letters were detected more rapidly and why they prompted superior recall of words in the present study. Also, this might explain how readers remember not to pronounce silent letters when they are reading words aloud. According to evidence presented by Householder (1971), Kerek (1976), and Ehri (Note 2), speakers who become familiar with the spellings of words are under some pressure to change their pronunciations to conform to spellings. Such a marking operation would identify one source of resistance to such shifts.

An alternative explanation for silent-letter effects can also be formulated. It may be that effects arose not from lexical storage processes in the past history of learners, but from episodic experiences in the experiment itself. Subjects performed three tasks with the target words. Silent letters may have been judged faster and may have prompted superior recall because of events occurring in preceding tasks (Bjork, 1975). For example, the act of reading the words and omitting silent letters from pronunciations may have distinguished these letters in memory and speeded up their detection in the judgment task that followed. Because of their unusual status, the act of detecting silent letters in imagined spellings may have made these associations more memorable and more easily recalled subsequently. However, one could counter that if silent letters attracted special attention here, they probably also attracted attention when spellings were first learned. Also, evidence in Experiment 2 can be interpreted against this hypothesis. Two letterjudgment trials did not enhance the magnitude of the silent-letter effect over one trial, as one might expect if episodic events created the effect. Which is the more accurate explanation for present findings awaits further study.
It is worth noting that although the letter-judgment task is on the face of it a visual memory search task, it was clear from present findings that processes involved in performing the task are not strictly visual but involve phonetic processing. Whether letters were silent or pronounced affected performance. Also, whether absent letters were plausible or implausible symbols for sounds affected performance. Interestingly, a parallel finding has also been reported. Spellings stored in memory have been found to influence performance in strictly auditory word processing tasks (Ehri \& Wilce, 1979, 1981; Seidenberg \& Tanenhaus, 1979; Jakimik, Cole, \& Rudnicky, Note 3). These findings appear contrary to the view that visual representations of words are coded and stored separately in memory (Baron, 1977; Barron, 1978). Rather, they suggest an interactive view of orthographic representations. Although the form of the representation is visual, its function is to symbolize sounds. It is by exercising this function that forms become interpretable, secured in memory, and wedded to sound (Ehri, 1980a).

Since the evidence from this study was intended to bear on our theory of printed-word learning, we selected young readers who had only recently become familiar with the spellings of our target words (i.e., secondgraders, third-graders, and first-term fourth-graders). It remains for future studies to determine whether older children and adults might also display the silent-letter effects reported here. It may be that as a result of their extensive experience reading these words and overlearning spellings, they have grown less sensitive to whether individual letters are pronounced or silent. Also, it remains for future studies to determine whether silentletter effects are more characteristic of good than of poor readers/spellers, who have poor memories for letters and who may not remember spellings by processing letter-sound relations. Although some evidence for this was reported in Experiment 5, further evidence is needed.

As suggested above, whereas younger readers may distinguish between silent and pronounced letters as they learn words, the distinction may become more complex as readers learn lots of spellings and notice regularities in lexical patterns. Smith (1980) identifies many functions served by silent letters, and he presents evidence that, among adults, whether silent Es are noticed in a letter-cancellation task varies according to their linguistic function in the spellings. Lexical Es (i.e., final silent $\mathrm{E}$ following $\mathrm{S}$ to exclude this word from the category of plurals: "horse") are detected more frequently than phonemic Es (i.e., final silent $\mathrm{E}$ changing the sound of a preceding vowel or consonant: "gate," "rage"), which in turn are detected more frequently than graphemic Es (i.e., final silent E having no effect on the sounds of other letters: "give"). In addition, combinations of these functions enhance their detectability over single functions. 
The involvement of silent letters in morphological rather than phonological rules was adopted by Frith (1978) to explain readers' superior ability to detect the omission of silent over pronounced letters in a proofreading task. However, it is unlikely that this explanation can handle the present findings, since our subjects were younger and probably insufficiently experienced with lexical spelling patterns to have acquired knowledge of morphological rules.

In conclusion, it is apparent that silent letters are processed differently from pronounced letters. Further research is needed to pursue these differences as they influence the course of printed-word learning: whether the distinction between silent and pronounced letters fades as readers learn more about lexical spelling patterns and become less attentive to single letter-sound correspondences and whether the detection and classification of letters as pronounced or silent varies as a function of the instructional method. Perhaps phonicstrained readers are more likely to notice and tag silent letters as exceptions in memory than are readers lacking a strong background in letter-sound mapping relations. Present findings underscore the importance of learning how orthography is grounded in sound during the course of reading acquisition. Without this, a refined sense of what is exceptional would not emerge. Many more letters would appear irregular and thus require memorization.

\section{REFERENCE NOTES}

1. Calfee, R. C., \& Calfee, K. H. Interactive reading assessment system (IRAS). Unpublished manuscript, Stanford University, 1977.

2. Ehri, L. C. Effects of printed language acquisition on speech. In D. Olson (Ed.), Nature and consequences of literacy. Book in preparation, 1982.

3. Jakimik, J., Cole, R. A., \& Rudnicky, A. I. The influence of spelling on speech perception. Paper presented at the annual meeting of the Psychonomic Society, St. Louis, November 1980.

\section{REFERENCES}

BARON, J. Mechanisms for pronouncing printed words: Use and acquisition. In D. LaBerge \& S. J. Samuels (Eds.), Basic processes in reading: Perception and comprehension. Hillsdale, N.J: Erlbaum, 1977.

Barron, R. W. Access to the meanings of printed words: Some implications for reading and for learning to read. In F. B. Murray (Ed.), The development of the reading process (International Reading Association Monograph No. 3). Newark, Del: International Reading Association, 1978.

Buork, R. A. Retrieval as a memory modifier. In R. Solso (Ed.), The Loyola Symposium (Vol. 2). Hillsdale, N.J: Erlbaum, 1975.
Cномsкy, C. Approaching reading through invented spelling. In L. B. Resnick \& P. A. Weaver (Eds.), Theory and practice of early reading (Vol. 2). Hillsdale, N.J: Erlbaum, 1979.

Corcoran, D. W. J. An acoustic factor in letter cancellation. Nature, 1966, 210, 658.

Corconan, D. W. J. Acoustic factor in proof reading. Nature, 1967, 214, 851-852.

Craik, F. I. M., \& Lockhart, R. S. Levels of processing: A framework for memory research. Journal of Verbal Learning and Verbal Behavior, 1972, 11, 671-684.

EHRI, L. C. Beginning reading from a psycholinguistic perspective: Amalgamation of word identities. In F. B. Murray (Ed.), The development of the reading process (International Reading Association Monograph No. 3). Newark, Del: International Reading Association, 1978.

EHRI, L. C. The development of orthographic images. In U. Frith (Ed.), Cognitive processes in spelling. London: Academic Press 1980. (a)

EHrI, L. C. The role of orthographic images in learning printed words. In J. F. Kavanagh \& R. Venezky (eds.), Orthography, reading and dyslexia. Baltimore, Md: University Park Press, 1980. (b)

EHRI, L. C., \& Roberts, K. Do beginners learn printed words better in context or isolation? Child Development, 1979, 50 , 675-685.

EHRI, L. C., \& WILCE, L. S. The mnemonic value of orthography among beginning readers. Journal of Educational Psychology, 1979, 71, 26-40.

EHRI, L. C., \& WILCE, L. S. The influence of orthography on reader's conceptualization of the phonemic structure of words. Applied Psycholinguistics, 1981, 2, 371-385.

Frith, U. From print to meaning and from print to sound, or How to read without knowing how to spell. Visible Language, $1978,12,43-54$

Hatch, E., Polin, P., \& Part, S. Acoustic scanning and syntactic processing: Three reading experiments-First and second language learners. Journal of Reading Behavior, 1974, 6, 275-285.

Householder, F. Linguistic speculations. London: Cambridge University Press, 1971.

KerEK, A. The phonological relevance of spelling pronunciation. Visible Language, 1976, 10, 323-338.

Seidenberg, M. S., \& Tanenhaus, M. K. Orthographic effects on rhyme monitoring. Journal of Experimental Psychology: Human Learning and Memory, 1979, 5, 546-554.

Sмгтн, P. T. Linguistic information in spelling. In U. Frith (Ed.), Cognitive processes in spelling. London: Academic Press, 1980.

Thonndike, E. L., \& LoRge, I. The teacher's word book of 30,000 words. New York: Teachers College Press, 1944.

VENEZKY, R. The structure of English orthography. The Hague: Mouton, 1970.

\section{NOTE}

1. We are grateful to Uta Frith for pointing out this difference.

(Received for publication March 2, 1981; revision accepted December 2,1981 .) 